\title{
Preface: Special Issue on Stochastic Games
}

\author{
Andrzej S. Nowak • Eilon Solan • Sylvain Sorin
}

Published online: 2 February 2013

(C) Springer Science+Business Media New York 2013

To celebrate the 60th anniversary of the seminal paper "Stochastic Games" of L.S. Shapley [16], Dynamic Games and Applications is proud to publish this special issue. Shapley's paper on stochastic games has had a tremendous scientific impact on the theory and applications of dynamic games and there is still a very active research on these domains. In addition, as can be seen by the content of this volume, the theoretical model as well the potential for applications develops in new directions including continuous time framework, link with evolutionary games, algorithmic game theory, economics, and social networks.

The idea to devote a special issue to celebrate the 60th anniversary of Shapley's paper [16] emerged a few years ago, and the decision was taken in 2011. Since then, we had the great pleasure to enjoy the attribution to Llyod Shapley of the Sveriges Riksbank Prize in Economic Sciences in Memory of Alfred Nobel 2012 "for the theory of stable allocations and the practice of market design," jointly with Alvin Roth. This is the occasion to recall the importance of Shapley's contributions in other areas of game theory like:

- core for $T U$ and $N T U$ cooperative games;

- equivalence principle for large economies;

- matching (with David Gale);

\footnotetext{
${ }^{1}$ The reader may visit: http://www.nobelprize.org/nobel_prizes/economics/laureates/2012/.

A.S. Nowak ( $\square)$

Faculty of Mathematics, Computer Science and Econometrics, University of Zielona Góra, Zielona Góra, Poland

e-mail: a.nowak@wmie.uz.zgora.pl

E. Solan

School of Mathematical Sciences, Tel-Aviv University, Tel-Aviv, Israel

e-mail: eilons@post.tau.ac.il

S. Sorin

Faculté de Mathématiques, Université Pierre et Marie Curie, Paris, France

e-mail: sorin@math.jussieu.fr
} 
- cooperative games with a continuum of players (with Robert Aumann);

- Shapley value and other power indices;

- repeated games (with information lag, survival);

- fictitious play and the Shapley triangle;

- potential noncooperative games (with Dov Monderer);

- simple games, convex games;

- price mechanisms;

- fixed points and index of equilibria.

The papers included in this volume cover only a part of the area of stochastic games. Their references give a lot of information on the existing literature on this topic. We would like to point out, however, that the impact of Shapley's article [16] on the theory of stochastic games is much larger than this volume shows. It cannot be described in detail in a short introduction to this volume. To give a more complete picture of the state of the art in the area of stochastic games, we include a list of useful references for basic (classical) results and surveys of earlier advances and related areas, like incomplete information and repeated games:

- Markov decision processes [3, 8];

- zero-sum repeated games, the Shapley operator, the asymptotic approach and the uniform approach [12-14, 19];

- games with signals and link to incomplete information games [12-14, 19];

- nonzero-sum games: asymptotic and uniform approach [14, 17, 20];

- Nash and correlated equilibria [2, 12-15, 17, 20];

- links with quitting games and stopping games [17, 18];

- infinite state space stochastic games [8,11, 13, 14, 17];

- algorithms and dynamics for stochastic games [4, 5, 7, 13, 14];

- turnpike theorems for Markov games, overtaking optimality [10];

- stochastic games with weakly continuous transitions and robust policies in dynamic economic models (growth theory) [8];

- applications in computer science, telecommunication, and economics [1, 2, 7, 8, 14];

- stochastic strategic market games [6,9].

We would like to thank the contributors to this special volume. We are also grateful to Georges Zaccour, the Editor-in-Chief, for inviting us to edit this issue and for facilitating the editorial process. Special thanks are also due to all the reviewers for their criticisms and suggestions, without whom this issue would not have been possible. We are also grateful to the editorial team in Springer for very good cooperation and constant help.

\section{References}

1. Altman E, Boulogne T, El-Azouzi R, Jiménez T, Wynter L (2006) A survey on networking games in telecommunications. Comput Oper Res 33(2):286-311

2. Dutta PK, Sundaram R (1998) The equilibrium existence problem in general Markovian games. In: Majumdar M (ed) Organizations with incomplete information. Cambridge University Press, Cambridge, pp 159-207

3. Feinberg EA, Shwartz A (eds) (2002) Handbook of Markov decision processes. Kluwer Academic, Boston

4. Filar JA, Raghavan TES (1991) Algorithms for stochastic games: a survey. Z Oper-Res 35(6):437-472

5. Filar JA, Vrieze K (1997) Competitive Markov decision processes-theory, algorithms and applications. Springer, New York 
6. Geanakoplos J, Karatzas I, Shubik M, Sudderth WD (1994) A class of strategic market games with active bankruptcy. J Math Econ 34:359-396

7. Haurie A, Krawczyk JB, Zaccour G (2012) Games and dynamic games. World Scientific, Singapore

8. Jaśkiewicz A, Nowak AS (2011) Stochastic games with unbounded payoffs: applications to robust control in economics. Dyn Games Appl 1(2):253-279

9. Karatzas I, Shubik M, Sudderth WD (1992) Construction of stationary Markov equilibria in a strategic market game. Math Oper Res 19(4):975-1006

10. Kolokoltsov V, Yang W (2012) Turnpike theorems for Markov games. Dyn Games Appl 2(3):294-312

11. Maitra AP, Sudderth WD (1996) Discrete gambling and stochastic games. Springer, New York

12. Mertens J-F (2002) Stochastic games. In: Aumann RJ, Hart S (eds) Handbook of game theory with economic applications, vol 3. Elsevier, Amsterdam, pp 1809-1832

13. Mertens J-F, Sorin S, Zamir S (1994) Repeated games. CORE discussion papers 9420-22. Cambridge University Press (to be published)

14. Neyman A, Sorin S (eds) (2003) Stochastic games and applications. NATO science series C, vol 570. Kluwer Academic, Dordrecht

15. Raghavan TES, Ferguson TS, Parthasarathy T, Vrieze OJ (eds) (1991) Stochastic games and related topics. In honor of professor L.S. Shapley. Kluwer Academic, Dordrecht

16. Shapley LS (1953) Stochastic games. Proc Natl Acad Sci USA 39:1095-1100

17. Solan E (2009) Stochastic games. In: Meyers RA (ed) Encyclopedia of complexity and systems science. Springer, Berlin, pp 8698-8708

18. Solan E, Vieille N (2005) Stopping games-recent results. In: Advances in dynamic games. Annals of the international society of dynamic games, vol 7. Springer, Berlin, pp 235-245

19. Sorin S (2002) A first course on zero-sum repeated games. Springer, New York

20. Vieille N (2002) Stochastic games: recent results. In: Aumann RJ, Hart S (eds) Handbook of game theory with economic applications, vol 3. Elsevier, Amsterdam, pp 1833-1850 